\title{
Buffering Agent-Induced Lactose Content Increases via Growth Hormone-Mediated Activation of Gluconeogenesis in Lactating Goats
}

\author{
L. LI ${ }^{1}$, M. L. HE ${ }^{1}$, Y. LIU ${ }^{1}$, Y. S. ZHANG ${ }^{1}$ \\ ${ }^{1}$ Key Laboratory of Animal Physiology and Biochemistry, College of Veterinary Medicine, Nanjing \\ Agricultural University, Nanjing, China
}

Received July 19, 2017

Accepted September 12, 2017

On-line January 5, 2018

\section{Summary}

Dairy goats are often fed a high-concentrate $(\mathrm{HC})$ diet to meet their lactation demands; however, long-term concentrate feeding is unhealthy and leads to milk yield and lactose content decreases. Therefore, we tested whether a buffering agent is able to increase the output of glucose in the liver and influence lactose synthesis. Eight lactating goats were randomly assigned to two groups: one group received a $\mathrm{HC}$ diet (Concentrate : Forage $=6: 4, \mathrm{HG}$ ) and the other group received the same diet with a buffering agent added $\left(0.2 \% \mathrm{NaHCO}_{3}\right.$, $0.1 \% \mathrm{MgO}, \mathrm{BG}$ ) over a 19-week experimental period. The total volatile fatty acids and lipopolysaccharide (LPS) declined in the rumen, which led the rumen $\mathrm{pH}$ to become stabile in the $\mathrm{BG}$ goats. The milk yield and lactose content increased. The alanine aminotransferase, aspartate transaminase, alkaline phosphatase, pro-inflammatory cytokines, LPS and lactate contents in the plasma significantly decreased, whereas the prolactin and growth hormone levels increased. The hepatic vein glucose content increased. In addition, pyruvate carboxylase (PC), phosphoenolpyruvate carboxykinase (PEPCK) and glucose-6phosphatase (G6PC) expression in the liver was significantly up-regulated. In the mammary glands, the levels of glucose transporter type $1,8,12$ as well as of sodium-glucose cotransporter 1 increased. Cumulative buffering agent treatment increased the blood concentrations of glucose via gluconeogenesis and promoted its synthesis in the liver. This treatment may contribute to the increase of the milk yield and lactose synthesis of lactating goats.

\section{Key words}

Buffering agent $\bullet$ High-concentrate diet $\bullet$ Lactose - Hepatic gluconeogenesis

\section{Corresponding author}

Y. S. Zhang, Key Laboratory of Animal Physiology and Biochemistry, College of Veterinary Medicine, Nanjing Agricultural University, Nanjing 210095, China. Fax: +86-2584395335. E-mail: zhangyuanshu@njau.edu.cn

\section{Introduction}

In the dairy industry, it is currently common practice to feed lactating cows or goats a high-concentrate (HC) diet to meet their energy requirements and support high milk production. However, long-term feeding of $\mathrm{HC}$ diet is harmful to the health of ruminants and leads to a decrease of the milk yield ( $\mathrm{Xu}$ et al. 2015). A previous study reported that feeding $\mathrm{HC}$ diets to lactating cows causes a decline in the rumen $\mathrm{pH}$ if organic acids, such as volatile fatty acid (VFA) and lactic acid, accumulate in the rumen (Chen and Oba 2012). Digestion of an $\mathrm{HC}$ diet results in a lower production of saliva and bicarbonate as well as a reduced buffering capacity coupled with a greater accumulation of organic acids, and the diet has been reported to increase the incidence of subacute ruminal acidosis (SARA) (Emmanuel et al. 2008). A rumen $\mathrm{pH}$ of less than 5.6 for over $3 \mathrm{~h}$ per day is used as a parameter to determine the occurrence of SARA (Gozho et al. 2005, Xie et al. 2015). In addition, a decrease in rumen $\mathrm{pH}$ results in the release of lipopolysaccharides (LPS), which originate from the cell-wall component of Gram-negative bacteria (Li et al. 2017). Previous studies have shown that LPS can translocate into the bloodstream from the digestive tract under high-permeability conditions after an injury to the liver tissue (Duanmu et al. 2016). 
In ruminants, lactose constitutes approximately $40 \%$ of the total solids in milk. Because lactose maintains the osmolarity of milk, the rate of lactose synthesis serves as a major control of the volume of the milk yield (Neville et al. 1983). Glucose is the main precursor of lactose synthesis in epithelial cells of the mammary gland; however, the mammary gland cannot synthesize glucose from other precursors due to the lack of glucose 6-phosphatase (G6PC) (Threadgold and Kuhn 1979). Therefore, the mammary gland is dependent on blood to meet its glucose needs, and as a result, mammary glucose uptake is a rate-limiting factor for the milk yield (Kronfeld 1982). Liver glycometabolism of ruminants is different from that of monogastric animals. In lactating dairy cows, glucose is primarily supplied by hepatic gluconeogenesis to maintain stable blood glucose (Reynolds 2006). Dairy cows experience an increased demand for glucose to support their whole-body glucose metabolism and supply glucose for lactose synthesis (Li et al. 2013). Therefore, liver gluconeogenesis plays an important role in lactose synthesis of the mammary gland.

A buffering agent may be able to enhance the acid base buffer capacity and has been used to prevent ruminant rumen SARA and improve primarily production performance. Previous studies have indicated that the addition of sodium bicarbonate $\left(\mathrm{NaHCO}_{3}\right)$ and magnesium oxide $(\mathrm{MgO})$ to a diet given to lactating cows increases the lactose content as well as the milk yield (Duan et al. 2000). It is well-documented that dietary addition of $2 \%$ $\mathrm{NaHCO}_{3}$ could increase the buffering capacity and prevent acidosis in the rumen (Islam et al. 2014). However, current research on buffering agents is focused on the composition and production of milk from dairy cows. Furthermore, little is known about the mechanism of how a buffering agent improves the milk yield and lactose content in goats. In this study, we created a buffering agent consisting of $0.2 \% \mathrm{NaHCO}_{3}$ and $0.1 \%$ $\mathrm{MgO}$ and combined it with a $\mathrm{HC}$ diet that was fed to lactating goats. We then investigated the effects of this buffering agent on the development of SARA and milk yield as well as the lactose content to determine the potential mechanisms of this phenomenon.

\section{Methods}

\section{Ethical approval}

The Institutional Animal Care and Use Committee of Nanjing Agricultural University (Nanjing,
People's Republic of China) approved all of the procedures (surgical procedures and care of goats). The protocol for this study was reviewed and approved under project number 2011CB100802. The slaughter and sampling procedures strictly followed the 'Guidelines on Ethical Treatment of Experimental Animals' (2006) no. 398 created by the Ministry of Science and Technology in China as well as 'Regulation regarding the Management and Treatment of Experimental Animals' (2008) no. 45 from the Jiangsu Provincial People's Government.

\section{Animals and experimental procedures}

Eight healthy multiparous mid-lactating Saanen goats (mean body weight \pm SEM, 39 $\pm 7 \mathrm{~kg}$, 3-4 weeks postpartum) of ages ranging from 2-4 years were used in the experiments. They were housed in individual stalls in a standard animal feeding house at Nanjing Agricultural University (Nanjing, China). All goats were randomly divided into two groups: one group received a $\mathrm{HC}$ diet (Concentrate $:$ Forage $=6: 4, \mathrm{HG}, \mathrm{n}=4$ ) and the other group received the same diet with a buffering agent added $\left(0.2 \% \mathrm{NaHCO}_{3}, 0.1 \% \mathrm{MgO}\right.$, purchased from Nanjing Jiancheng Bioengineering Institute, China, $\mathrm{BG}, \mathrm{n}=4)$. The ingredients and nutritional composition of the diets are presented in Table 1. The animals were fed the respective diets for 19 weeks, and they had free access to water during the experimental period. Prior to the initiation of the experiment, all goats had rumen fistula and hepatic catheters installed. After surgery, goats were observed for 2 weeks during recovery. Sterilized heparin saline $(500 \mathrm{IU} / \mathrm{ml}, \quad 0.3 \mathrm{ml} /$ time $)$ was administered at 8-h intervals every day until the end of the experiment to prevent the catheters from becoming blocked.

\section{Rumen fluid collection and analysis}

Fifteen minutes prior to feed delivery and 0, 2, 4, 6,8 and $10 \mathrm{~h}$ after feed delivery on 7 consecutive days during week 19, $20 \mathrm{ml}$ of ruminal fluids were collected with a nylon bag, and the $\mathrm{pH}$ value was measured immediately with a $\mathrm{pH}$-meter.

Ruminal fluid was collected and each sample was transferred into a 50-ml sterile tube and kept on ice until it was transported to the laboratory for initial processing before LPS determination. Another part of each ruminal fluid sample was centrifuged at 3,200 $\times \mathrm{g}$ for $10 \mathrm{~min}$ at $4{ }^{\circ} \mathrm{C}$ immediately after collection, and the supernatant was collected. To analyze the VFA in ruminal fluid, a 5-ml aliquot was deproteinized with $1 \mathrm{ml}$ 
Table 1. Composition and nutrient levels of the experimental diets.

\section{Concentrate : Forage ratio 6:4}

$\begin{array}{lc}\text { Ingredient (\%) } & \\ \text { Leymus chinensis } & 27.00 \\ \text { Alfalfa silage } & 13.00 \\ \text { Corn } & 23.24 \\ \text { Wheat bran } & 20.77 \\ \text { Soybean meal } & 13.67 \\ \text { Limestone } & 1.42 \\ \text { NaCl } & 0.30 \\ \text { Premix } & \text { Total } \\ \end{array}$

$\begin{array}{lc}\text { Nutrient level }^{b} & \\ \text { Net energy (MJ.kg } & \\ \text { Crude protein (\%) } & 6.71 \\ \text { Neutral detergent fibre (\%) } & 16.92 \\ \text { Acid detergent fibre (\%) } & 31.45 \\ \text { Calcium (\%) } & 17.56 \\ \text { Phosphorus (\%) } & 0.89 \\ \end{array}$

${ }^{a}$ Provided per $\mathrm{kg}$ of diet: vitamin A $6,000 \mathrm{IU} / \mathrm{kg}$, vitamin D 2,500 IU/kg， vitamin E $80 \mathrm{mg} / \mathrm{kg}$ ， Cu $6.25 \mathrm{mg} / \mathrm{kg}$ ， Fe $62.5 \mathrm{mg} / \mathrm{kg}$, Zn $62.5 \mathrm{mg} / \mathrm{kg}$, Mn $50 \mathrm{mg} / \mathrm{kg}$ ， I $0.125 \mathrm{mg} / \mathrm{kg}$ ， Co $0.125 \mathrm{mg} / \mathrm{kg}$. ${ }^{\text {b }}$ Nutrient levels were measured according to National Research Council methods (2001).

of $25 \%$ metaphosphoric acid. These samples were stored at $-20{ }^{\circ} \mathrm{C}$ until analysis.

The concentration of LPS in ruminal fluid was measured using a Chromogenic End-point Tachypleus Amebocyte Lysate Assay Kit (Chinese Horseshoe Crab Reagent Manufactory Co. Ltd, Xiamen, China). Pre-treated ruminal fluid samples were diluted until their LPS concentrations were in the range of 0.1-1.0 endotoxin units $(\mathrm{EU}) / \mathrm{ml}$ relative to the reference endotoxin.

VFA were measured using capillary column gas chromatography (GC-14B, Shimadzu, Japan; capillary column: $\quad 30 \mathrm{~m} \times 0.32 \mathrm{~mm} \times 0.25 \mathrm{~mm}$ film thickness; column temperature $=110^{\circ} \mathrm{C}$, injector temperature $=$ $180^{\circ} \mathrm{C}$, detector temperature $=180^{\circ} \mathrm{C}$ ).

\section{Plasma biochemical parameters analysis}

At the $19^{\text {th }}$ week, blood samples were collected from the jugular vein, hepatic vein and portal vein blood in 10-ml vacuum tubes containing sodium heparin. Blood was centrifuged at $3,000 \times \mathrm{g}$ for $15 \mathrm{~min}$ to separate plasma, which was then stored at $-20^{\circ} \mathrm{C}$ until analysis. The plasma glucose content was quantified using a Beckman Kurt AU5800 series automatic biochemical analyzer (Beckman Kurt, California, USA) at the General Hospital of Nanjing Military Region (Nanjing, China).

The growth hormone $(\mathrm{GH})$, tumor necrosis factor- $\alpha(\mathrm{TNF}-\alpha)$, and interleukin $1 \beta$ (IL-1 $\beta$ ) concentrations in the plasma were measured by radioimmunoassay with commercially available human radioimmunoassay kits purchased from the Beijing North Institute of Biological Technology. The detection ranges of the radioimmunoassay kits for GH (rabbit, B12PZA), TNF- $\alpha$ (rabbit, C06PZA) and IL-1 $\beta$ (rabbit, C09PDA) were $0.1-50 \mathrm{ng} / \mathrm{ml}, 1-10 \mathrm{ng} / \mathrm{ml}$ and $0.1-8.1 \mathrm{ng} / \mathrm{ml}$, respectively. All of the procedures were performed according to the manufacturer's instructions.

Analyses of prolactin, glucocorticoids, histamine and lactate were performed using an Enzyme-Linked Immunosorbent Assay (ELISA) kit (Shanghai Enzymelinked Biotechnology Co. Ltd, Shanghai, China) according to the manufacturer's instructions. The detection ranges of the ELISA kits for prolactin, glucocorticoids, histamine and lactate were $5-2,000 \mathrm{pg} / \mathrm{ml}$, 0-80 ng/ml, 2-600 ng/ml and 0.1-30 $\mathrm{mmol} / \mathrm{ml}$, respectively. The LPS concentration was determined using a chromogenic endpoint assay (CE64406, Chinese Horseshoe Crab Reagent Manufactory Co., Ltd., Xiamen, China) with a minimum detection limit of $0.01 \mathrm{EU} / \mathrm{ml}$. The procedures were performed according to the manufacturer's instructions.

\section{Milk composition analysis}

Goats were milked at 8:30 $\mathrm{h}$ and $18: 30 \mathrm{~h}$, and the milk yield was recorded daily. A 50-ml milk sample was taken to determine the lactose content once a week (Milk-Testing Milkoscan 4000, FOSS, Hillerød, Denmark) at the Animal Experiment Centre of College of Animal Science and Technology at Nanjing Agricultural University.

\section{Sample collection}

At the $19^{\text {th }}$ week, mammary gland tissues were obtained by biopsy $4 \mathrm{~h}$ after the morning feeding. Local anesthesia ( $2 \%$ lidocaine hydrochloride) was administered to the breast skin in a circular pattern surrounding the incision site; then, a 2-cm incision was made and mammary gland tissue was dissected. Tissue samples (500-800 mg) were rinsed with $0.9 \%$ saline, snap frozen 
in liquid nitrogen and used for RNA extraction. Goats were slaughtered after fasting overnight. The incisions were sutured and antibiotics were administered intramuscularly to avoid infection.

After 19 weeks, all goats were killed via neck vein injections of xylazine $[0.5 \mathrm{mg} \text { ( } \mathrm{kg} \text { body weight })^{-1}$; Xylosol; Ogris Pharme, Wels, Austria] and pentobarbital [50 mg (kg body weight) ${ }^{-1}$; Release; WDT, Garbsen, Germany]. After slaughter, liver tissue was collected and washed twice with cold physiological saline $(0.9 \% \mathrm{NaCl})$ to remove blood. The livers were then transferred into liquid nitrogen and used for RNA and protein extraction.

RNA isolation, cDNA synthesis and real-time PCR

Total RNA was extracted from liver samples using TRIzol reagent (15596026, Invitrogen, Carlsbad, USA) and converted to cDNA using commercial kits (Vazyme, Nanjing, China). All of the PCR primers were synthesized by the Generay Company (Shanghai, China), and the primer sequences are listed in Table 2. PCR was performed using the AceQ qPCR SYBR Green Master Mix Kit (Vazyme, Nanjing, China) and MyiQ2 Real-time PCR System (Bio-Rad, California, USA) with the following cycling conditions: $95^{\circ} \mathrm{C}$ for $2 \mathrm{~min}, 40$ cycles of $95^{\circ} \mathrm{C}$ for $15 \mathrm{~s}$ and $60^{\circ} \mathrm{C}$ for $30 \mathrm{~s}$. Glyceraldehyde 3-phosphate dehydrogenase (GAPDH) served as a reference for normalization. The $2^{-\Delta \Delta \mathrm{Ct}_{\text {method }} \text { was }}$ used to analyze the real-time PCR results, and each gene mRNA level is expressed as the fold-change relative to the mean value of the control group.

Table 2. Primer sequences and product sizes.

\begin{tabular}{|c|c|c|}
\hline Target genes & Primer sequences (5'-3') & Products/bp \\
\hline \multirow{2}{*}{$G 6 P C$} & CCCACAGCTTCAACAAACTCTT & \multirow{2}{*}{230} \\
\hline & GATGTCCATGCCATTCTCCTT & \\
\hline \multirow{2}{*}{ PEPCK } & CCCTACTCTCCCGGGATGGAAAGT & \multirow{2}{*}{306} \\
\hline & GCCCTCCGAAGATGATGCCCTCAA & \\
\hline \multirow{2}{*}{$P C$} & CCCACAGCTTCAACAАAСТCTT & \multirow{2}{*}{352} \\
\hline & GATGTCCATGCCATTCTCCTT & \\
\hline \multirow{2}{*}{ GLUT1 } & AGACACCTGAGGAGCTGTTC & \multirow{2}{*}{233} \\
\hline & GACATCACTGCTGGCTGAAG & \\
\hline \multirow{2}{*}{ GLUT8 } & TGGCATCTACAAGCCCTTCA & \multirow{2}{*}{244} \\
\hline & ACCATGACCACACCTGACAA & \\
\hline \multirow{2}{*}{ GLUT12 } & ACGTGACCATGGTACCTGTT & \multirow{2}{*}{321} \\
\hline & TCCCAAGTTCATACCCCACC & \\
\hline \multirow{2}{*}{$S G L T 1$} & GCAAGAGAGTCAATGAGCCG & \multirow{2}{*}{235} \\
\hline & ATGGCCAGGATGACGATGAT & \\
\hline \multirow{2}{*}{$G H R$} & TTGGAATACTTGGGCTAACA & \multirow{2}{*}{262} \\
\hline & GACCCTTCAGTCTTCTCATCG & \\
\hline \multirow{2}{*}{$G A P D H$} & GGGTCATCATCTCTGCACCT & \multirow{2}{*}{177} \\
\hline & GGTCATAAGTCCCTCCACGA & \\
\hline
\end{tabular}

\section{Western blot analysis}

Total protein was extracted from frozen liver samples, and the concentration was determined using a bicinchoninic acid (BCA) assay kit (Pierce, Rockford, IL, USA). We isolated $30 \mu \mathrm{g}$ of total protein from each sample, which were subjected $10 \%$ SEMS-PAGE. The separated proteins were transferred onto nitrocellulose membranes (Bio Trace, Pall Co., Port Washington, USA). The blots were incubated with the following primary antibodies overnight at $4{ }^{\circ} \mathrm{C}$ at dilutions of $1: 1,000$ in block: rb-anti-phosphoenolpyruvate carboxykinase (rb-anti-PEPCK, \#12940, CST), rb-anti-glucose transporter type 1 (rb-anti-GLUT1, ab14683, Abcam, Cambridge, UK) and rb-anti-glucose transporter type 12 (rb-anti-GLUT12, ab100993, Abcam, Cambridge, UK). An rb-anti-GAPDH primary antibody (A531, Bioworld, Nanjing, China, 1:10,000) was also incubated with the blots to provide a reference for normalization. 
After washing the membranes, incubation with HRP-conjugated secondary antibody was performed for $2 \mathrm{~h}$ at room temperature. Finally, the blots were washed, and the signal was detected by enhanced chemiluminescence (ECL) using the LumiGlo substrate (Super Signal West Pico Trial Kit, Pierce, USA). The ECL signal was recorded using an imaging system (BioRad, USA) and analyzed with Quantity One software (Bio-Rad, USA).

\section{Statistical analysis}

The results were expressed as the mean \pm SEM. The data for ruminal $\mathrm{pH}$ and glucose in plasma from the hepatic, portal and jugular veins were analyzed for differences due to diet, feeding time, and any interactions between these variables by univariate analysis using the General Linear Models in SPSS 11.0 for Windows (StatSoft, Inc., Tulsa, OK, USA). The differences in milk yield, lactose content, plasma biochemical index, mRNA and protein expression between the two groups were analyzed by the Independent-Samples $\mathrm{T}$ test using the Compare Means of SPASS 11.0 for Windows (StatSoft, Inc., Tulsa, OK, USA). Data were considered statistically significant if $\mathrm{p}<0.05, \mathrm{p}<0.01$. The numbers of replicates used for statistics are noted in the Tables and Figures. All experiments were performed in triplicate $(n=3)$.

\section{Results}

Buffering agent treatment increased the daily milk yield and lactose content in lactating goats

From week 1 to week 2, there were no significant differences in the average daily milk yield and lactose content between BG goats and HG goats. However, the average daily milk yield $(\mathrm{p}<0.05)$ and lactose content $(p<0.05)$ increased significantly in the BG goats from 3-19 weeks of treatment compared to the HG goats (Fig. 1).
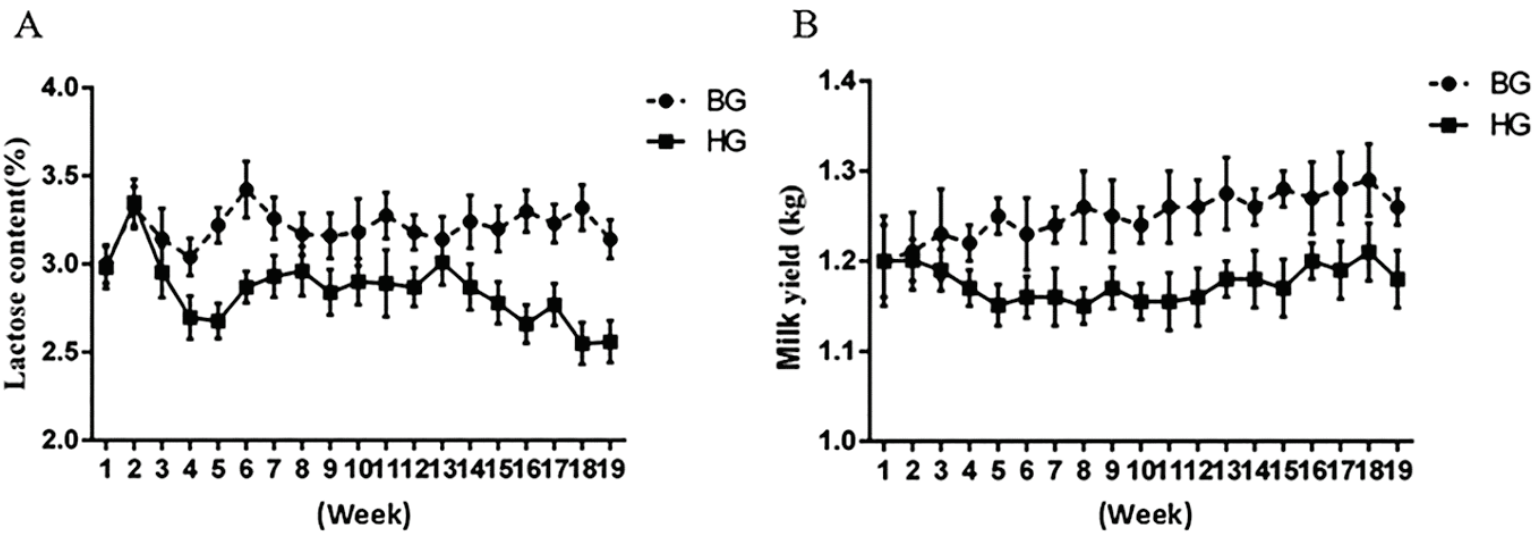

Fig. 1. Comparison of the average weekly lactose content and milk yield between the buffering agent (BG) and high-concentrate diet groups (HG). Values are shown as the means \pm SEM, $n=4$ /group. ${ }^{*} p<0.05$ compared to the HG.

Buffering agent treatment stabilized the ruminal fluid $\mathrm{pH}$ in lactating goats fed a $\mathrm{HC}$ diet

After 19 weeks of providing the BG diet, the dynamic $\mathrm{pH}$ curve in the $\mathrm{BG}$ goats was higher than that of the HG goats during the long-term experiment. The results showed that a $\mathrm{pH}$ value under 5.6 lasted for $4 \mathrm{~h}$ in the HG goats, which indicated that SARA was successfully induced. The $\mathrm{pH}$ value of the BG goats was significantly increased compared to the $\mathrm{pH}$ values in the $\mathrm{HG}$ goats $(\mathrm{p}<0.05)$. However, the ruminal $\mathrm{pH}$ was significantly affected by the digestion time, whereas there was no interaction between the digestion time and diet and ruminal $\mathrm{pH}$ (Fig. 2).

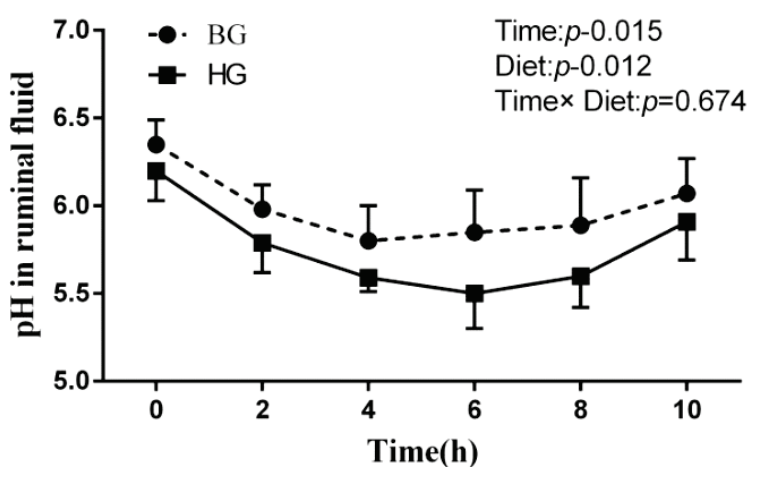

Fig. 2. $\mathrm{pH}$ value in ruminal fluid after a 19-week feeding regimen. Data were analyzed for differences due to diet, time, and variable interactions by univariate analysis using the General Linear Models in SPSS 11.0 for Windows (StatSoft, Inc., Tulsa, OK, USA). Values are the mean \pm SEM, $n=4$ /group. ${ }^{*} p<0.05$ compared to the HG. 
Table 3. Effects of the buffering agent treatment on the rumen fermentation parameters in goats.

\begin{tabular}{lccc}
\hline Item & BG & HG & p-value \\
\hline LPS $(E U / m l)$ & $26201 \pm 2398$ & $40395 \pm 4723$ & $0.002 * *$ \\
Total VFA $(m M)$ & $90.20 \pm 6.55$ & $116.37 \pm 10.14$ & $0.04^{*}$ \\
Acetate $(m M)$ & $58.28 \pm 2.45$ & $65.48 \pm 5.45$ & 0.39 \\
Propionate $(m M)$ & $17.01 \pm 0.25$ & $22.45 \pm 1.51$ & $0.03 *$ \\
Butyrate $(m M)$ & $12.65 \pm 1.27$ & $18.36 \pm 1.79$ & $0.02^{*}$ \\
Acetate : Propionate & $3.41 \pm 0.58$ & $2.9 \pm 0.21$ & 0.11 \\
Propionate : Butyrate & $1.34 \pm 0.05$ & $1.22 \pm 0.12$ & $0.03 *$ \\
\hline
\end{tabular}

BG, buffering agent group; HG, high-concentrate diet group; LPS, lipopolysaccharide; VFA, volatile fatty acid. Values are shown as the means \pm SEM, $n=4 /$ group. $* p<0.05, * * p<0.01$ compared to the $H G$.

\section{$V F A$ and LPS concentrations in ruminal fluid}

As shown in Table 3, BG goats had a significantly lower LPS concentration in ruminal fluid compared to HG goats $(\mathrm{p}<0.01)$. The concentrations of total VFA, propionate, and butyrate in ruminal fluid were significantly decreased in $B G$ goats compared to $\mathrm{HG}(\mathrm{p}<0.05)$. However, the ratio of propionate to butyrate in the rumen was significantly elevated in the $\mathrm{BG}$ goats $(\mathrm{p}<0.05)$.

Buffering agent treatment changed plasma hormones, enzymes, primary pro-inflammatory cytokines and metabolites produced in lactating goats

As shown in Table 4, the plasma contents of alanine aminotransferase (ALT), aspartate transaminase (AST) and alkaline phosphatase (AKP) were significantly lower in the BG goats compared to the $\mathrm{HG}$ goats $(\mathrm{p}<0.05)$. Although the plasma content of lactic dehydrogenase (LDH) declined, there was no significant difference between the $\mathrm{BG}$ and $\mathrm{HG}$ goats. The pro-inflammatory cytokines, including TNF- $\alpha$ and IL-1 $\beta$, in BG goats were significantly lower compared to HG goats $(p<0.05)$. Meanwhile, we found that the metabolism products of LPS as well as the histamine and lactate contents were also lower in BG goats compared to HG goats. Among them, LPS and lactate were significantly different $(p<0.05)$. Furthermore, BG goats showed significantly higher levels of $\mathrm{GH}$ and a higher prolactin concentration in plasma compared to HG goats, while there was no significant difference in the glucocorticoid concentrations of plasma between BG and HG goats.

Buffering agent treatment regulated the enzymes required for glucose transfer in the mammary gland of lactating goats

We found that mRNA expression of glucose transporter type 1 (GLUT1), glucose transporter type 8 (GLUT8), glucose transporter type 12 (GLUT12) and sodium-glucose cotransporter 1 (SGLT1) was higher in BG goats compared to $\mathrm{HG}$ goats. In particular, expression of GLUT1 and SGLT1 was significantly higher compared to that of HG goats $(p<0.05)$. The level of GLUT1 protein expression in the mammary gland was significantly up-regulated in BG goats compared to $\mathrm{HG}$ goats $(\mathrm{p}<0.05)$. Additionally, protein expression of GLUT12 in BG goats was increased compared to HG goats (Fig. 3).

Buffering agent treatment increased the production of glucose in the liver

After 19 weeks of feeding goats an BG diet, the jugular and hepatic vein contents of glucose significantly increased in the $\mathrm{BG}$ goats compared to the $\mathrm{HG}$ goats $(\mathrm{p}<0.05)$. The portal vein content of glucose increased, but there was no significant difference between the BG and $\mathrm{HG}$ goats. Compared to the HG goats, we found that the glucose content of the BG goats was significantly higher in the hepatic vein compared to the portal vein $(p<0.05$, Table 5). This outcome indicates that more glucose is produced in the liver. It is possible that synthesis of glucose was activated following treatment with the buffering agent.

Buffering agent treatment regulated enzymes required for gluconeogenesis and GHR in the livers of lactating goats

We found that mRNA expression of phosphoenolpyruvate carboxykinase (PEPCK) and pyruvate carboxylase (PC) as well as glucose-6phosphatase (G6PC) was higher in BG goats compared to HG goats. In particular, expression of PEPCK and G6PC were significantly higher in $\mathrm{BG}$ goats compared to the HG goats $(p<0.05)$. The level of PEPCK protein 
expression in the liver was significantly up-regulated in BG goats compared to HG goats $(\mathrm{p}<0.05)$. This result is consistent with our previous observation that PEPCK mRNA expression was increased in BG goats (Fig. 4). Taken together, these results suggest that treatments with the buffering agent promoted gluconeogenesis in the liver. The level of GHR expression in the liver was significantly up-regulated in BG goats compared to HG goats $(\mathrm{p}<0.05$, Fig. 5).

Table 4. Effects of the buffering agent treatment on plasma enzyme, primary pro-inflammatory cytokines, produced metabolites and hormones of lactating goats.

\begin{tabular}{|c|c|c|c|}
\hline Item & BG & HG & p-value \\
\hline$A L T(I U / l)$ & $40.33 \pm 4.84$ & $77.67 \pm 12.44$ & $0.03 *$ \\
\hline$A S T(I U / l)$ & $43.33 \pm 8.48$ & $71.33 \pm 10.67$ & $0.04 *$ \\
\hline$L D H(I U / l)$ & $233.66 \pm 16.45$ & $243.66 \pm 13.54$ & 0.66 \\
\hline$A K P(I U / l)$ & $149.67 \pm 17.07$ & $213.5 \pm 20.50$ & $0.02 *$ \\
\hline$T N F-\alpha(n g / m l)$ & $2.47 \pm 0.30$ & $4.61 \pm 0.48$ & $0.03 *$ \\
\hline$I L-1 \beta(n g / m l)$ & $0.74 \pm 0.03$ & $0.79 \pm 0.05$ & $0.04 *$ \\
\hline$L P S(E U / m l)$ & $2.01 \pm 0.24$ & $3.62 \pm 0.50$ & $0.03 *$ \\
\hline Histamine $(\mathrm{ng} / \mathrm{ml})$ & $1.99 \pm 0.06$ & $2.11 \pm 0.09$ & 0.09 \\
\hline Lactate (mmol/l) & $0.95 \pm 0.05$ & $1.39 \pm 0.16$ & $0.04 *$ \\
\hline Prolactin $(\mathrm{pg} / \mathrm{ml})$ & $436.57 \pm 37.78$ & $353.29 \pm 30.59$ & $0.04 *$ \\
\hline Glucocorticoids (ng/ml) & $10.2 \pm 1.67$ & $9.8 \pm 2.56$ & 0.08 \\
\hline Growth hormone (ng/ml) & $0.94 \pm 0.08$ & $0.63 \pm 0.03$ & $0.03 *$ \\
\hline
\end{tabular}

BG, buffering agent group; $\mathrm{HG}$, high-concentrate diet group; ALT, alanine aminotransferase; AST, aspartate transaminase; $L D H$, lactic dehydrogenase; AKP, alkaline phosphatase; TNF-a, tumor necrosis factor-a; IL-1 $\beta$, interleukin $1 \beta$; LPS, lipopolysaccharide. Values are shown as the means \pm SEM, $n=4$ /group. ${ }^{*} p<0.05$ compared to the HG.

Table 5. The average concentrations of glucose in plasma from hepatic, portal and jugular veins of lactating goats.

\begin{tabular}{|c|c|c|c|c|c|}
\hline \multirow{2}{*}{ Glucose (mmol/l) } & \multirow{2}{*}{ BG } & \multirow{2}{*}{ HG } & \multicolumn{3}{|c|}{ Effect, p-value } \\
\hline & & & Diet & Time & Diet $\times$ Time \\
\hline \multicolumn{6}{|l|}{ Hepatic vein } \\
\hline$O h$ & $3.34 \pm 0.37^{*}$ & $3.01 \pm 0.18$ & 0.003 & 0.292 & 0.636 \\
\hline $4 h$ & $3.35 \pm 0.37 *$ & $3.15 \pm 0.18$ & & & \\
\hline $8 h$ & $3.44 \pm 0.37 *$ & $3.07 \pm 0.18$ & & & \\
\hline \multicolumn{6}{|l|}{ Portal vein } \\
\hline$O h$ & $3.27 \pm 0.11$ & $3.26 \pm 0.13$ & 0.102 & 0.902 & 0.494 \\
\hline $4 h$ & $3.28 \pm 0.12$ & $3.27 \pm 0.12$ & & & \\
\hline $8 h$ & $3.27 \pm 0.09$ & $3.25 \pm 0.15$ & & & \\
\hline \multicolumn{6}{|l|}{ Jugular vein } \\
\hline$O h$ & $3.30 \pm 0.05$ & $3.27 \pm 0.09$ & 0.002 & 0.890 & 0.579 \\
\hline $4 h$ & $3.33 \pm 0.24$ & $3.29 \pm 0.12$ & & & \\
\hline $8 h$ & $3.34 \pm 0.14$ & $3.25 \pm 0.04$ & & & \\
\hline
\end{tabular}

BG, buffering agent group; $\mathrm{HG}$, high-concentrate diet group. Values are shown as the means $\pm \mathrm{SEM}, \mathrm{n}=4 / \mathrm{group}$. ${ }^{*} \mathrm{p}<0.05$ compared to the HG. 

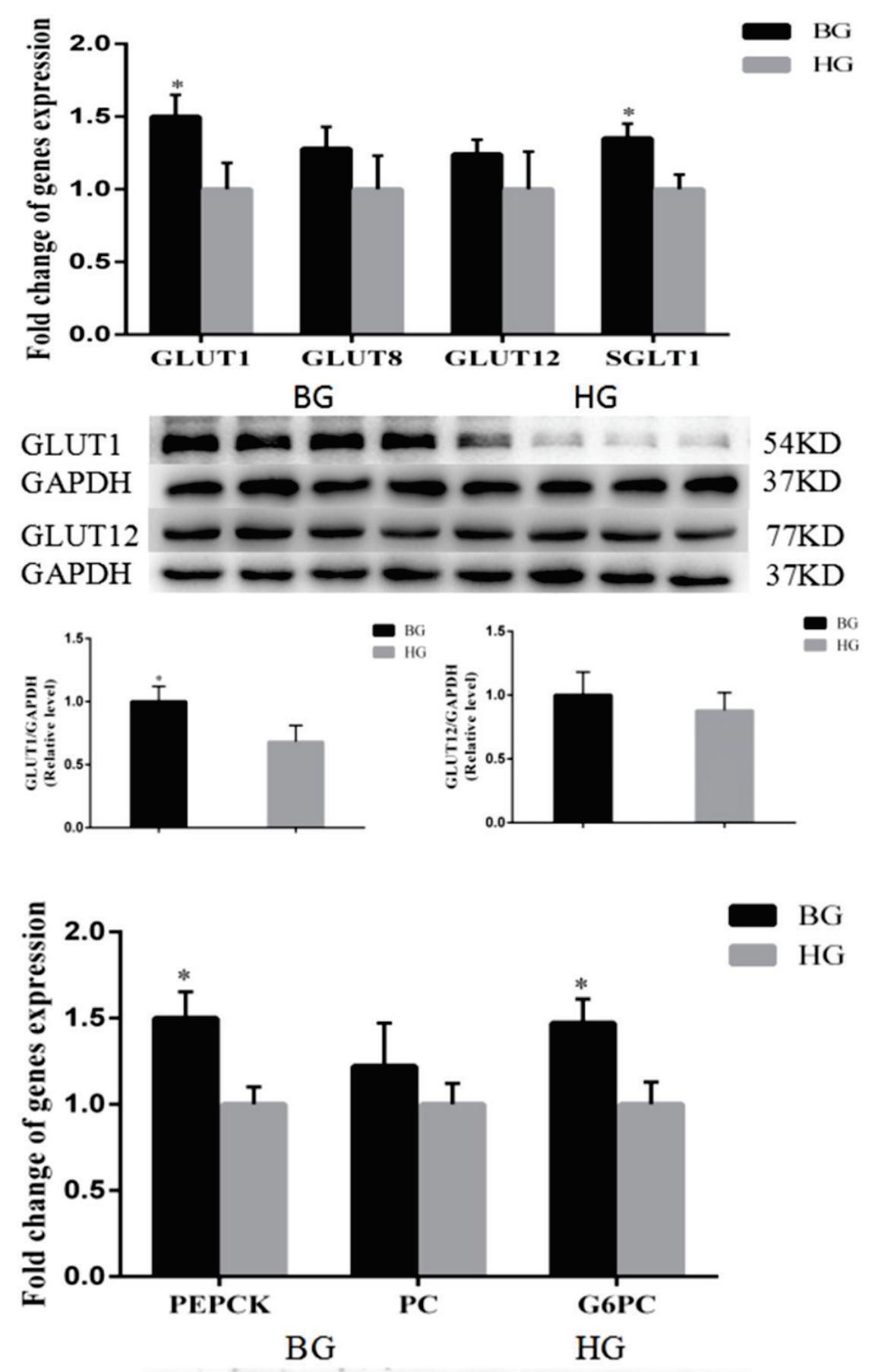

PEPCK - - - - - $63 \mathrm{KD}$
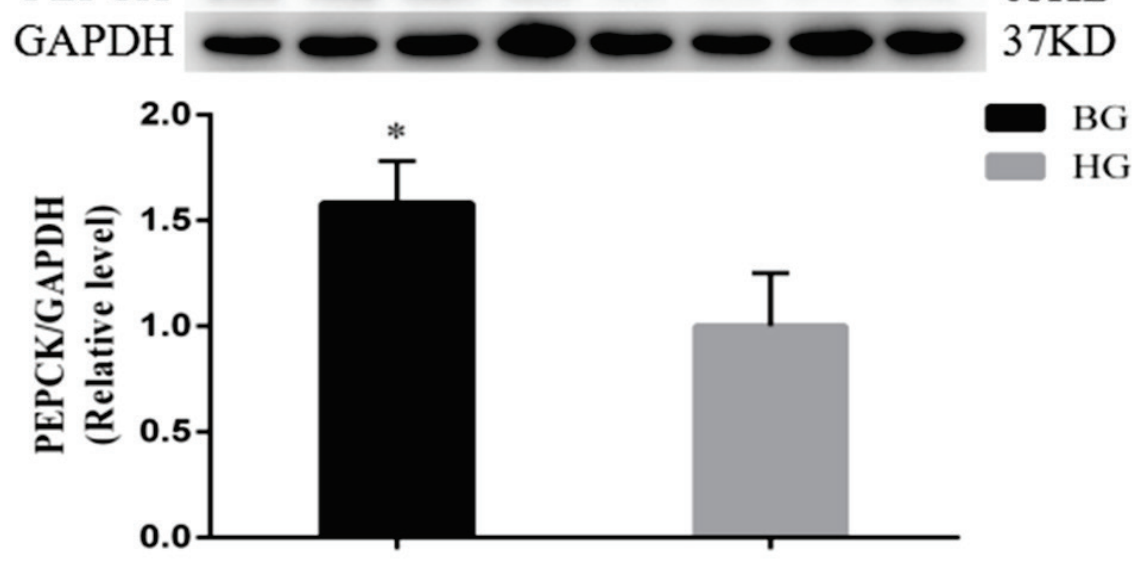

Fig. 3. Effects of buffering agent treatment on the expression of mammary gland glucose transfer genes in lactating goats. Values are shown as the means \pm SEM, $\mathrm{n}=3$. $* \mathrm{p}<0.05$ compared to the HG.

Fig. 4. Effects of buffering agent treatment on the expression of liver gluconeogenesis genes in lactating goats. Values are shown as the means \pm SEM, $n=3$. ${ }^{*} \mathrm{p}<0.05$ compared to the HG. 


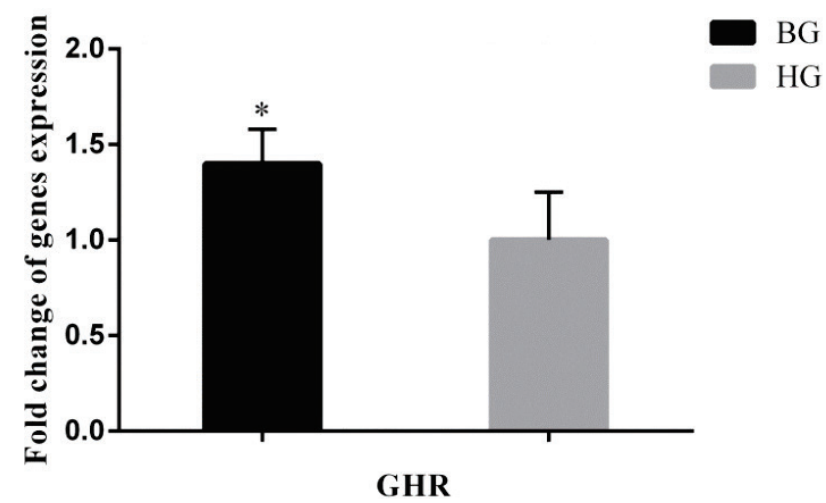

Fig. 5. Effects of buffering agent treatment on the expression of GHR in the livers of lactating goats. Values are shown as the means $\pm S E M, n=3 . * p<0.05$ compared to the HG.

\section{Discussion}

Currently, dairy goats are often fed HC diets to meet the energy demands for high milk yields. However, consumption of $\mathrm{HC}$ diets is harmful to the health of dairy goats (Chang et al. 2015, Li et al. 2017). It has been well-documented that feeding $\mathrm{HC}$ diets to ruminants results in SARA, which is a common metabolic disease that commonly occurs in high-producing animals. The root cause of SARA involves excessive amounts of rapidly fermentable non-structural carbohydrates that increase the accumulation of organic acids and shift the microbial population in the gastrointestinal tract of ruminants (Plaizier et al. 2008). Furthermore, an increased amount of fermentable carbohydrates, such as starch, pass through the fore-stomach to the intestinal tract through acidosis, which accelerates intestinal tract fermentation (Beauchemin et al. 2003, Li et al. 2013). This increase in carbohydrates ultimately affects the intestinal absorption of nutrients. Importantly, previous research showed that feeding ruminants a $\mathrm{HC}$ diet for a long period of time could reduce the lactose content and milk yield (Chang et al. 2015).

$\mathrm{NaHCO}_{3}$ increases the buffering capacity and prevent acidosis in the rumen. It was reported that the rumen $\mathrm{pH}$ profile improved and there was a higher yield of milk and milk solids when $\mathrm{NaHCO}_{3}$ was added to a $\mathrm{HC}$ diet (Cruywagen et al. 2015). Previous studies indicated that the addition of $\mathrm{NaHCO}_{3}$ and $\mathrm{MgO}$ to restricted-roughage rations for goats increased the content of lactose and milk yield (Lee and Hsu 1991). Prolactin is involved in the development of the mammary gland, and the start and continuation of lactation influences lactogenesis. Prolactin is found in milk, is responsible for the synthesis of lactose and affects milk production (Alipanah et al. 2007). In our experiment, a rumen $\mathrm{pH}$ of less than 5.6 lasted for $4 \mathrm{~h}$ in goats that were fed a HC diet. According to the definition of experimental SARA, HG goats were suffering from SARA. However, after feeding goats a BG diet for 19 weeks, the buffering agent added to the $\mathrm{HC}$ diet stabilized the ruminal $\mathrm{pH}$ and prevented the occurrence of SARA. Meanwhile, an increase in the milk yield and lactose content was observed in the BG goats. The concentrations of prolactin in blood were also markedly increased. Therefore, increased levels of prolactin in blood are associated with the milk yield and lactose content improvement.

It is well known that feeding HC diets leads to the translocation of LPS from Gram-negative bacteria in the gastrointestinal tract into the circulating blood. Other studies have shown that feeding lactating goats a diet containing $60 \%$ concentrate led to elevated blood LPS concentrations (Dong et al. 2013). The increased levels of circulating LPS also elevated the concentration of the pro-inflammatory cytokines IL-1 $\beta$ and TNF- $\alpha$ in the blood and increased activation of liver inflammatory responses (Duanmu et al. 2016). The biochemical parameters ALT, AST and AKP in peripheral blood are common indicators that are used to assess the status of liver function (Sevinc et al. 2001). In particular, ALT is a specific parameter that reflects hepatocyte damage. In the present study, we observed that feeding goats an HC diet induced a massive release of LPS in the rumen, which triggered a local or systemic inflammatory response after the translocation of LPS into the bloodstream. Furthermore, our data demonstrated that feeding goats an HC diet significantly increased the concentrations of LPS, TNF- $\alpha$ and IL- $1 \beta$ in the plasma. The increase in pro-inflammatory cytokines in the blood is consistent with the translocation of LPS and activation of inflammatory responses. In addition, the concentrations of ALT, ALP and AKP in peripheral blood were also higher in $\mathrm{HG}$ goats compared to BG goats. These results show that feeding $\mathrm{HC}$ diets to goats resulted in a breach of hepatocytes, releasing enzymes into circulation. Importantly, the results showed that the concentrations of pro-inflammatory cytokines, including LPS, TNF- $\alpha$ and IL-1 $\beta$, in the plasma of BG goats were significantly lower compared to those of HG goats. Therefore, we hypothesized that the buffering agent added to the $\mathrm{HC}$ diet reduced the release of rumen LPS and stabilized the body health of lactating goats.

Compared to monogastric animals, glucose is 
primarily supplied by hepatic gluconeogenesis to maintain stable blood glucose content in ruminants (Reynolds 2006). Therefore, the liver plays a crucial physiological role in the body and is responsible for glucose metabolism. Our study showed that feeding an $\mathrm{HC}$ diet to lactating goats for long periods of time led to an LPS-cytokine-induced inflammatory response, and this response increased the consumption and catabolism of glucose in the liver (Jiang et al. 2013). GH is a polypeptide hormone that is synthesized and secreted by the anterior pituitary gland and plays a key role in regulating ruminant mammary gland development and lactation (Akers 2006). GH is important for regulating glycometabolism due to its promotion of gluconeogenesis in the liver (Emmison et al. 1991). A healthy body is essential for normal production of hormones. However, increased translocation of LPS into the brain via the blood enhances the inflammatory response, which might ultimately affect the levels of growth hormone. PEPCK and G6PC are two key hepatic gluconeogenic enzymes, and the expression and activity of these enzymes increased hepatic glucose output (Lochhead et al. 2000). $\mathrm{PC}$ is the first regulatory enzyme in the gluconeogenic pathway that converts pyruvate to oxaloacetate in gluconeogenesis (Pershing et al. 2002). Major glucose precursors in the ruminant liver include propionate, amino acids and lactate. It has been documented that the increased proportion of propionate may be related to glycogenesis in ruminants. Because most VFA emerges in the portal vein after absorption from the digestive tract (Bergman et al. 1990), alterations of the proportions of propionate influence gluconeogenesis in the liver. Therefore, liver gluconeogenesis plays a crucial physiological role in maintaining the body blood sugar levels because it is the main organ for glucose storage in the form of glycogen, as well as for endogenous glucose production (Sharab et al. 2015). Our results indicated that addition of a buffering agent to the HC diet significantly decreased the total VFA, propionate and butyrate levels in ruminal fluid. However, the ratio of propionate to butyrate increased in the BG goats. We also observed that the buffering agent treatment promoted expression of PEPCK, PC and G6PC, indicating that gluconeogenesis in the liver increased. In addition, the $\mathrm{BG}$ diets increased the glucose content in hepatic veins. The plasma GH and GHR levels were also increased in BG goats because elevated GH increases the glucose content and activity of gluconeogenesis in the liver. Meanwhile, the buffering agent added to the $\mathrm{HC}$ diet inhibited the consumption of glucose and stabilized the liver health of lactating goats. Taken together, these findings suggest that feeding goats BG diets can promote liver gluconeogenesis due to the increased proportion of propionate in the rumen as well as the increased entry of glucose into the blood through the hepatic vein.

In lactating animals, providing glucose to the mammary gland is a metabolic priority because glucose is the primary precursor for lactose synthesis in the mammary gland. Once taken up by lactating mammary epithelial cells, glucose is either used in the synthesis of lactose or processed by glycolysis to provide energy. Lactose is synthesized from free glucose and uridine diphosphate (UDP)-galactose by lactose synthase catalysis (Watkins et al. 1962). The mammary gland itself cannot synthesize glucose from other precursors because of the lack of glucose-6-phosphatase (Scott et al. 1976). Therefore, the mammary gland is dependent on the blood supply for to meet its glucose requirement. In addition, lactose maintains the osmolarity of milk, and the rate of lactose synthesis is a major factor that influences the milk yield. The results also indicated that lactose synthesis and the milk yield showed a linear or positive correlation with glucose uptake in the mammary gland of goats and cows (Cant et al. 2002). Glucose uptake in the mammary gland increased dramatically during lactation. Prior research has shown that glucose transport across the plasma membranes of mammalian cells is carried out by 2 distinct processes: facilitative transport, which is mediated by a family of facilitative glucose transporters (GLUT), and sodium-dependent transport, which is mediated by $\mathrm{Na}^{+} /$glucose cotransporters (SGLT) (Zhao and Keating 2007a). An early study demonstrated that facilitated GLUT1, GLUT8, GLUT12 and SGLT1 have different expression levels in mammary glands (Zhao and Keating 2007b). GLUT1 is ubiquitously expressed in lactating cow tissues, is most abundant in the mammary glands and kidneys and has its lowest expression in omental fat and skeletal muscle (Zhao et al. 1993). SGLT1 plays an important role in glucose transport in Golgi membranes (Faulkner et al. 1981). In our experiment, we found that the glucose content in the plasma of the jugular vein increased in the BG goats compared to the HG goats. GLUT1, GLUT8, GLUT12 and SGLT1 expression in mammary glands was also elevated in BG goats. Additionally, the level of GLUT1 protein was significantly enhanced in the mammary glands of BG goats. Taken together, these results indicate that 
a buffering agent added to the $\mathrm{HC}$ diet led to the translocation of more glucose from the peripheral blood into mammary epithelial cells and consequently increased the milk yield and lactose content.

In summary, we systematically investigated the effects of a buffering agent on milk quality in lactating goats and found that both the milk yield and lactose content were increased. Furthermore, the blood GH and prolactin levels were increased in BG goats, which increased hepatic gluconeogenesis and activity. Activated gluconeogenesis increases the levels of blood glucose released from the liver. Therefore, increased glucose in hepatic veins when goats are fed a BG diets may play a key role in increasing the milk yield and lactose synthesis of lactating goats. However, GLUT1, GLUT8, GLUT12 and SGLT1 expression in mammary glands was also elevated in BG goats. It is possible that the buffering agent added to the $\mathrm{HC}$ diet inhibited the release of inflammatory cytokines and stabilized the mammary glands of lactating goats. The buffering agent also likely caused an increase in glucose transporters in the mammary gland and prolactin levels in the blood, which could also increase the lactose content in milk. Therefore, further research is needed to determine the underlying mechanisms.

\section{Conflict of Interest}

There is no conflict of interest.

\section{Acknowledgements}

This work was supported by grants from the National Basic Research Program of China (project No. 2011CB100802), the National Nature Science Foundation of China (project No. 31172371) and the Priority Academic Program Development of Jiangsu Higher Education Institutions (PAPD).

\section{References}

AKERS RM: Major advances associated with hormone and growth factor regulation of mammary growth and lactation in dairy cows. J Dairy Sci 89: 1222-1234, 2006.

ALIPANAH M, KALASHNIKOVA L, RODIONOV G: Association of prolactin gene variants with milk production traits in Russian Red Pied cattle. Iran J Biotechnol 5: 158-161, 2007.

BEAUCHEMIN KA, YANG WZ, RODE LM: Effects of particle size of alfalfa-based dairy cow diets on chewing activity, ruminal fermentation, and milk production. J Dairy Sci 86: 630-643, 2003.

BERGMAN EN: Energy contributions of volatile fatty acids from the gastrointestinal tract in various species. Physiol Rev 70: 567-590, 1990.

CANT JP, TROUT DR, QIAO F, PURDIE NG: Milk synthetic response of the bovine mammary gland to an increase in the local concentration of arterial glucose. J Dairy Sci 85: 494-503, 2002.

CHANG G, ZHANG K, XU T, JIN D, SEYFERT HM, SHEN X, ZHUANG S: Feeding a high-grain diet reduces the percentage of LPS clearance and enhances immune gene expression in goat liver. BMC Vet Res 11: 67, 2015.

CHEN Y, OBA M: Variation of bacterial communities and expression of Toll-like receptor genes in the rumen of steers differing in susceptibility to subacute ruminal acidosis. Vet Microbiol 159: 451-459, 2012.

CRUYWAGEN CW, TAYLOR S, BEYA MM, CALITZ T: The effect of buffering dairy cow diets with limestone, calcareous marine algae, or sodium bicarbonate on ruminal $\mathrm{pH}$ profiles, production responses, and rumen fermentation. J Dairy Sci 98: 5506-5514, 2015.

DONG H, WANG S, JIA Y, NI Y, ZHANG Y, ZHUANG S, SHEN X, ZHAO R: Long-term effects of subacute ruminal acidosis (SARA) on milk quality and hepatic gene expression in lactating goats fed a high-concentrate diet. PLoS One 8: e82850, 2013.

DUAN LX, ZHANG RH, GAERDI, AORIGELE, HASTONGLAGA: Effects of supplementing by-pass protein and buffer additives in the diet of lactating cows on milk output and composition. J Inner Mongol Agricult Univ 21: 29-34, 2000.

DUANMU Y, CONG R, TAO S, TIAN J, DONG H, ZHANG Y, NI Y, ZHAO R: Comparative proteomic analysis of the effects of high-concentrate diet on the hepatic metabolism and inflammatory response in lactating dairy goats. J Anim Sci Biotechnol 7: 5, 2016.

EMMANUEL DG, DUNN SM, AMETAJ BN: Feeding high proportions of barley grain stimulates an inflammatory response in dairy cows. J Dairy Sci 91: 606-614, 2008. 
EMMISON N, AGIUS L, ZAMMIT VA: Regulation of fatty acid metabolism and gluconeogenesis by growth hormone and insulin in sheep hepatocyte cultures. Effects of lactation and pregnancy. Biochem J 274: 21-26, 1991.

FAULKNER A, CHAIYABUTR N, PEAKER M, CARRICK DT, KUHN NJ: Metabolic significance of milk glucose. J Dairy Res 48: 51-56, 1981.

GOZHO GN, PLAIZIER JC, KRAUSE DO, KENNEDY AD, WITTENBERG KM: Subacute ruminal acidosis induces ruminal lipopolysaccharide endotoxin release and triggers an inflammatory response. $J$ Dairy $S c i$ 88: 1399-1403, 2005.

HUHTANEN P, VANHATALO A, VARVIKKO T: Effects of abomasal infusions of histidine, glucose, and leucine on milk production and plasma metabolites of dairy cows fed grass silage diets. J Dairy Sci 85: 204-216, 2002.

ISLAM SMS, HOSSAIN MA, HASHIM MMA, SARKER MSA, PAUL AK: Effects of sodium bicarbonate on induced lactic acidosis in Black Bengal goats. Wayamba J Anim Sci 6: 1044-1057, 2014.

JIANG X, ZENG T, ZHANG S, ZHANG Y: Comparative proteomic and bioinformatic analysis of the effects of a highgrain diet on the hepatic metabolism in lactating dairy goats. PloS One 8: e80698, 2013.

KRONFELD DS: Major metabolic determinants of milk volume, mammary efficiency, and spontaneous ketosis in dairy cows. J Dairy Sci 65: 2204-2212, 1982.

LI L, CAO Y, XIE Z, ZHANG Y: A high-concentrate diet induced milk fat decline via glucagon-mediated activation of AMP-activated protein kinase in dairy cows. Sci Rep 7: 44217, 2017.

LI S, KHAFIPOUR E, KRAUSE DO, KROEKER A, RODRIGUEZ-LECOMPTE JC, GOZHO GN, PLAIZIER JC: Effects of subacute ruminal acidosis challenges on fermentation and endotoxins in the rumen and hindgut of dairy cows. J Dairy Sci 95: 294-303, 2012.

LI WQ, BU DP, WANG JQ, NAN XM, SUN P, ZHOU LY: Effect of two different diets on liver gene expression associated with glucose metabolism in dairy cows. Livest Sci 158: 223-229, 2013.

LEE MJ, HSU AL: Effect of supplementation of sodium bicarbonate and magnesium oxide in diet on lactating performance and rumen characteristics of dairy goats. J Chin Soc Anim Sci 20: 431-442, 1991.

LOCHHEAD PA, SALT IP, WALKER KS, HARDIE DG, SUTHERLAND C: 5-aminoimidazole-4-carboxamide riboside mimics the effects of insulin on the expression of the 2 key gluconeogenic genes PEPCK and glucose6-phosphatase. Diabetes 49: 896-903, 2000.

NEVILLE MC, ALLEN JC, WATTERS C: The mechanisms of milk secretion. In: Lactation: Physiology, Nutrition and Breast-Feeding. NEVILLE MC, NEIFERT MR (eds), Plenum Press, New York, 1983, pp 49-104.

PERSHING RA, MOORE SD, DINGES AC, THATCHER WW, BADINGA L: Short communication: hepatic gene expression for gluconeogenic enzymes in lactating dairy cows treated with bovine somatotropin. $J$ Dairy Sci 85: 504-506, 2002.

PLAIZIER JC, KRAUSE DO, GOZHO GN, MCBRIDE BW: Subacute ruminal acidosis in dairy cows: the physiological causes, incidence and consequences. Vet J 176: 21-31, 2008.

REYNOLDS CK: Production and metabolic effects of site of starch digestion in dairy cattle. Anim Feed Sci Technol 130: 78-94, 2006.

SCOTT RA, BAUMAN DE, CLARK JH: Cellular gluconeogenesis by lactating bovine mammary tissue. $J$ Dairy Sci 59: 50-56, 1976.

SEVINC M, BASOGLU A, BIRDANE FM, BOYDAK M: Liver function in dairy cows with fatty liver. Rev Med Vet 152: 297-300, 2001.

SHARABI K, TAVARES CD, RINES AK, PUIGSERVER P: Molecular pathophysiology of hepatic glucose production. Mol Aspects Med 46: 21-33, 2015.

THREADGOLD LC, KUHN NJ: Glucose-6-phosphate hydrolysis by lactating rat mammary gland. Int J Biochem 10: 683-685, 1979.

WATKINS WM, HASSID WZ: Synthesis of lactose by particulate enzyme preparations from guinea pig and bovine mammary glands. Science 136: 329, 1962.

XIE ZL, YE PS, ZHANG SK, ZHANG YS, SHEN XZ: Endogenous LPS alters liver GH/IGF system gene expression and plasma lipoprotein lipase in goats. Physiol Res 64: 721-729, 2015. 
XU T, TAO H, CHANG G, ZHANG K, XU L, SHEN X: Lipopolysaccharide derived from the rumen down-regulates stearoyl-CoA desaturase 1 expression and alters fatty acid composition in the liver of dairy cows fed a highconcentrate diet. BMC Vet Res 11: 52, 2015.

ZHAO FQ, KEATING AF: Expression and regulation of glucose transporters in the bovine mammary gland. $J$ Dairy Sci 90: 76-86, 2007a.

ZHAO FQ, KEATING AF: Functional properties and genomics of glucose transporters. Curr Genomics 8: 113-128, $2007 \mathrm{~b}$.

ZHAO FQ, GLIMM DR, KENNELLY JJ: Distribution of mammalian facilitative glucose transporter messenger RNA in bovine tissues. Int J Biochem 25: 1897-1903, 1993. 